\title{
A Bio-Political Construction: The Representation of Refugees and Migrants. From the 'Reel' to the 'Real'
}

\author{
El-moutasam Aziz \\ The International University of Beirut \\ Michel Abi Chahla street, Mousytbeh \\ Beirut-Lebanon \\ elmoutasam.aziz@b-iu.edu.lb
}

\author{
Laila Manasfi \\ The International University of Beirut \\ Michel Abi Chahla street, Mousytbeh \\ Beirut-Lebanon \\ laila.manasfi@b-iu.edu.lb
}

\author{
Ghassan Salah \\ The International University of Beirut \\ Michel Abi Chahla street, Mousytbeh \\ Beirut-Lebanon \\ ghassansalah48@gmail.com
}

\begin{abstract}
The purpose of this paper is to explore to what extent information communication technologies affect public perception. An analytical review of innovative methods and applications of ICT's will be made. A deep analysis comparing local and global mainstream media coverage will be used to gauge the effects of the normalization of war and political strife imagery on public perception. Specifically a subset of migrants (e.g., Palestinian, Syrian) will be examined to assess the effects of this phenomenon on the refugee population in Lebanon. The results of this open-ended research endeavour will advance knowledge in human perception by gaining a better understanding of how communication technologies of the past and those of today compare the influx of Syrian refugees in Lebanon to that of Palestinians. Moreover, it questions how this migration influences the application of laws (that have been on the books but never applied), and what comparison can be made between media coverage of the Palestinian refugees of 1948 as opposed to Syrian refugees in today's post-modern mobile and satellite connectivity? Specifically, this study's scope revolves on how media representation facilitates negative or positive feelings towards the plight of refugees.
\end{abstract}

Keywords: Refugees, Migrant, Communication Technology, Media Coverage, Media Representation, Thermal Imaging Devices, Human Perception.

\section{INTRODUCTION}

As a result of the atrocities of the Second World War, European Jews migrated and settled in modern day Palestine in mass. This migration sparked armed conflict between these new comers and the indigenous Arab population of Palestine (i.e., Palestinians) which ultimately resulted in the illegal occupation of Palestinian land by European Jews and the diaspora (i.e. mass out migration) of the Palestinians from their ancestral Lands. This event, known as 'The Catastrophe' is generationally engrained in the Palestinian psyche to this day affecting not only the Palestinians that fled as a result of this illegal occupation but millions of their decedents in the ensuing decades causing their plight to be synonymous with human displacement in the modern era.
Within 21st century political context, the Middle East has become synonymous with armed conflict, insurgency, terrorism, and violence resulting from political strife both foreign and domestic. Calls for freedom and civil liberty from oppressed populations in this region were met by brutal crackdowns by entrenched regimes and tacit silence from world government resulting in a new mass wave of out migration by a populous fearing war, terrorism, and political reprisal in such places as Syria, Iraq, and Libya. Between the years 2011 and 2018, the war in Syria alone had left 6 million people internally displaced and another 5 million externally displaced. Predominantly these migrants sought safety in neighbouring countries such as Turkey, Lebanon, Jordan, and Egypt due to proximity while some risked their lives to traverse to more distant lands in Europe. Adding to the plight 
of these hopeless migrants are socio-political constructs (e.g., othering, severe food insecurity, harsh and harmful child labor, extreme poverty and lack of healthcare, etc.) within their already torn apart livelihood. Migrants lucky enough to survive made their way through the central, western and eastern Mediterranean routes leading into the Balkan states, and finally arriving at various destinations in Europe. Host countries perpetuated by both government and non-governmental entities that dehumanize these populations.

\section{SHOCK AND AWE}

'Shock and Awe', a tactic used by the US military in its attempt to paralyze and decapitate the Iraqi military's defence systems during the second gulf war. (i.e., 2003) ushered in an era in which warfare was personalized through the constant stream of military footage of precision strikes on military and civilian targets and through the lens of embedded journalist who accompanied military units as they conducted their operations in real time. Technological advances in media devices (e.g., smart phones) coupled with the accelerated dissemination of such images contributing to the normalization and desensitization of such images amount the world's population.

By the Mid 2000's the normalization of war footage had become mainstream. Human displacement imagery resulting from worldwide violence and armed conflict saturated the World Wide Web, global news outlets and social media sites. Specifically, the oversaturation of images of refugees from the Middle East and North Africa has placed the public in a complacent state of mind, being totally unaware of the dangers undermining the vulnerability of refugees and migrants in relation to their desperate, daunting, and life threatening journeys. This event has disrupted the lives of millions of people in what is considered the largest out migration since World War II. A major consequence of this saturation of imagery is the loss of humanistic empathy towards the plight of refugees, migrants and asylum seekers, to the point that this plight is viewed negatively in the public eye.

Recently, advances in communication technology, specifically different forms of weapons technology such as a thermal imaging device used by the conceptual documentarian Richard Mosse in his latest video installation 'Incoming' to map the refugee crisis in the Middle East, North Africa and Europe. Mosse uses an inventive method of technically modifying a thermal heat camera to positively impact public perception of refugees and migrants.

This innovation in weapons technology produces imagery that contributes to the dehumanization of refugees and migrants, by representing them as foreign bodies of thermal heat. This very same method is equally used to 're-humanize' them in the public's eye. He does this by depicting migrants in their most bare biological processes (e.g., stripping refugees of their individuality). Mosse explains, "Even at close range, the camera is unable to perceive that vehicle of emotional communication, the eye's pupils. Instead, it represents the eyes as viscous black jelly. The usual signals of human empathy are turned on their head. We are left confused, alienated, the world feels suddenly unfamiliar, new." In essence, this innovative method of conceptual documentary photography disrupts the bio-political agenda and saturation of refugee imagery that is portrayed by government. This disruption is made through a highly creative process which enhances the public point of view regarding the desperate circumstances of refugees and their uncanny imagery.

\section{THE NORMALIZATION OF A 'NEW REALITY'}

The purpose of this research is to explore innovative forms of communication technology (i.e., thermal heat imaging devices) and their effects on changing public and governmental points of view vis-à-vis refugee crisis in the Middle East. The study aims to shed light on this phenomenon by examining a subset of migrants (i.e., Syrians, and Palestinians) in Lebanon. The refugee population in Lebanon is a viable one, due to the fact that Lebanon has hosted a large share of these. According to the UNHCR, there were over 1 million Syrian refugees who had been registered in Lebanon in 2016, making it a suitable research site (Data2.unhcr.org, 2019).

The motivation underlying this research stems from a vision to highlight the refugee crisis in the Middle East through new and innovative means. We look forward to this open-ended endeavour to assess the extent that different forms of communication technology such as military-grade thermal heat cameras (like the one used by Richard Mosse), and Electronic/Satellite News Gathering (used by 
broadcast media), or, mobile connectivity (Mobile phones, tablets, social media etc.) used by the public affect the represented reality of refugees and migrants as influenced by bio-political government agendas. Moreover, the innovation and proliferation of information communication technology (ICT) in the past decades are evident. Research has shown that such technologies do in fact influence representations of reality. Contarello and Sarrica claim "The spread of ICTs constitutes an intriguing phenomenon for studying the interweaving between ways of knowing, thinking and experiencing new 'realities'." (A. Contarello, M. Sarrica, 2005, p. 1017). This is especially true of representations of ever-increasing Palestinian and Syrian migrant communities in Lebanon which we feel needs to be explored in more detail. We hope to expand on the political vision of government and society, specifically in countries where there are many cases of asylum. We as well aspire to witness the journey from the 'presentation' of new methods for the 'representation' of refugees to the masses, and seeing positive outcomes.

\section{BRIDGING THE GAP}

The mid-20th century brought increased migrations in the Middle East and Africa. Refugees, migrants and asylum seekers migrated to escape global warming, drought, war, and violence. Since 2010, and due to conflicts in Iraq, Syria and Palestine, there has been an increase in human displacement and in the visual representation of those displaced. This saturation has nullified any significance contained within the graphic images (i.e., refugees drowning, political strife, exploitation, death and etc.) of refugees and asylum seekers. The resulting factor can be witnessed in the lack of moral, ethical, humane treatment of refugees and migrants, and the absence of cognitive awareness and empathy from societies and governments alike. This emphasizes the failure to fill the gap between governmental, political and societal points of view. The already mute voice of refugees is doomed to failure and the discourse between government, laws, political agendas and societal influence should be broader and larger than sheer deliberate or unintended authoritarianism as in the case of Palestinian and Syrian refugees in Lebanon.

This on-going research will explore how government controlled or political party leaning or special interest group media use communication technology to flood media outlets with imagery of human displacement that undermine the essential character of refugees rather than presenting the actual state which conforms to their harsh reality. Overall affecting public opinion and manufacturing a public point of view that is indifferent towards the hardships of refugees.

This paper aims beyond to gain a better understanding of how communication technologies of the past and those of today compare and contrast the influx of Syrian refugees in Lebanon to that of the Palestinians. Moreover, it questions how this migration influences the application of laws (that have been on the books but never applied). What comparison can be made between media coverage of the Palestinian refugees of 1948 as opposed to Syrian refugees in today's post-modern mobile and satellite connectivity? And. How does media reel support this shift? What are the effects of political exclusion? Does social exclusion cause social isolation and a distortion of the general image of refugees in the perception of the public eye? What determination can be made in the dispute between societies and governments pertaining to the refugee crisis in the Middle East and in Lebanon? Specifically, this study's scope revolves on how media representation facilitates negative or positive feelings towards the plight of refugees.

\section{SHAPING PUBLIC PERCEPTION}

The reason this is important is although the proliferation of personalized communication technologies (e.g., smart phones, tablets, and laptops) gives the public a sense of independence from the control of mass media, the latter still holds significant sway in shaping public perceptions. Visual communication has a great influence on changing perception and how we view certain events in our crisis struck modern world. It is a tool that can be used to interpret differing outlooks between governmental, political and societal points of view. Today a higher level of public awareness can be achieved through understanding the role of how communication technology was used in the past (old media) in comparison to technology being used today (new media). This comparison yields to achieve transparency in dealing with refugees, migrants and asylum seekers as in the newest work of Richard Mosse 'Incoming'. Mosses use of a military-grade thermal camera imaging device to 
map the refugee crises in the Middle East, Africa and Europe has introduced a new understanding in employing innovative audio-visual means that result in the positive impact of how human displacement is perceived by government and the public. This shows that it is not necessarily the advancements in ICT's that are needed in order to properly expose such an imperceptible topic, but that the inventive means in which they are applied can be of great significance and have a strong influence on how we see.

Today, more artists and filmmakers are making ethical and responsible interventions and helping to give a new voice and image to refugees. Furthermore, images captured by Mosse from the shore of Lesbos are currently under investigation and could contain solid data on the failure of assisting drowning migrants by governmental agencies such as the European border and coast guard agency, Frontex. The advent of alternative communication technology could be a precursor and a catalyst in the implementation of human rights laws and the design and implementation of action plans for the response and rescue of refugees, invariably aiding to change government viewpoint and action in dealing with human displacement.

We claim that Palestinians are given a hard time even though they are semi-assimilated in Lebanese culture, seeing as Lebanese have ill feelings towards the growing Syrian refugee problem. Our argument calls for determining a mechanism of action for refugees based on human rights and not for political and social gains which leads to questions that drive this research study:

To what extent do the tools of communication technology affect the representational reality of the Middle Eastern refugee crisis to the masses?

What is the point of view of society regarding the existence of asylum seekers in a given society or a single state in contrast with, or in contradiction of the point of view of politics and government?

\section{A FORBIDDEN IMAGE}

In 2017, conceptual documentary photographer Richard Mosse presented his newest video installation 'Incoming' at The Barbican Curve Gallery in London. The new installation showcased an innovative image capturing device and although this wasn't the first time the Irish photographer experimented with new methods of filming technology, the result was revolutionary. In 2012, Mosse introduced 'The Enclave' from his work in the Congo. Mosse works with an infrared film stock (Kodak Aerochrome) intended to be used for vegetative surveying. The technology was used by the US military for government surveillance during the 2nd World War. The technology filters out the chlorophyll in healthy green vegetation causing a shift in the colour of plants from green to a vibrant pink that is reminiscent of a Martian planet that has yet to be explored. This has enabled the artist to capture what Mosse continuously labels as "the impossible image", an image that is difficult to construct and to define, perhaps even one that should not be seen. A forbidden image, (e.g., Muhammad al-Durrah, Alan Kurdi).

For 'Incoming' Mosse was inspired by wildlife cinematographer Sophie Darlington who shared her experience working with a military-grade camera which was developed by a multi-national weapons company and designed for battlefield awareness and long range border security and control. The camera is capable of detecting biological human bodies at a maximum distance of 33.3 kilometres. The medium-wave infrared technology is unable to transmit through glass, therefore the camera optics are manufactured from germanium, a rare earth mineral, allowing the thermal imaging unit to see in contours of heat, resulting in monochromatic images of refugees and migrants as they made their journey to Europe. With so many variables and moving parts of the camera, modifications needed to be made in order to make it suitable for documenting field work, after pleading with the manufacturer for modifications, Mosse received the modified version in 9 months. Today he still considers it "a technical nightmare" due to the fact that it was never intended to be used for artistic or documentary work. The camera had to be fitted with an X-box controller and special batteries allowing field work possible. The unit also supported an extreme telephoto lens which created a tunnel vision perspective of refugees and migrants. A major challenge for Mosse was getting the camera across borders since the camera is regarded as a weapon under international law. Mosse states, "To carry the camera across international borders without an official certificate of export clearance is regarded as a crime of weapons smuggling", this forced Mosse to work with an export lawyer to obtain permission from various consulates giving him the ability to travel 
across borders with the camera, a process which required great time and great effort.

Incoming is a video installation projected onto 3 meter wide screens accompanied by an audio track and several smaller TV sets screening audio-visual content. Since its projection 'Incoming' has posed significant questions pertaining to bio-politics and human perception, migration and asylum, climate change and hypothermia, as well as mortality. 'Incoming' depicts the refugee crisis in North Africa, the Middle East and Europe through a militarygrade weapon of thermal-heat to capture the biggest migration since World War II. 1.8 million Refugees journeyed across continents into Europe where many were observed and recorded from miles away as they migrated by sea through the eastern, central and western Mediterranean routes leading into different parts of Europe. Specifically, Mosse captured the refugees as they trekked from the east through the Persian Gulf and across the Turkish border as well as from the west through the Saharan desert to the Libyan coastline.

From thermal weapon to communication technology, the method with which Mosse employs this technology is ground breaking to say the least. Mosses methodology was to use the weapon against itself in ways it was never intended in order to see the refugees through the lens of government, as a foreign monochromatic body of heat, ultimately reducing the refugees to their most basic biological essence. Technological, experimental and narrative methods used by Mosse in his previous work 'The Enclave' and recently in 'Incoming' aims to revolutionize methods of altering human perception in dealing with human catastrophes such as human displacement, all in all, giving the public a multi-perception point of view.

The transparent thermal images of the refugees, display the camera's ability to create images with an uncanny simulacrum of migrants through a dehumanizing thermal heat mechanism stripping refugees and migrants of their individualism. The mapping, capturing and recording of images from a maximum distance of 33.3 kilometres allowed the portrayal of extensive realism as the refugees were not aware that they are being observed. Mosse explains, "So we captured some extremely authentic gestures - people asleep, people embracing each other, people at prayer. There's a stolen intimacy to it. There's no awareness, there's no self-consciousness. It's a two-step process - dehumanizing them and then making them human again." The technology nullifies any form of facial expression or personality; differences in ethnicity or culture, and gender or age are made null and void. It differentiates the refugees from the mainstream image of migrants and asylum seekers that we have grown accustomed to seeing through the lens of broadcasting, satellite, or the internet to an image with a multi-perceptual effect. Invariably, one may have grown accustomed to the inventive imagery presented by Richard Mosse as a way of experimenting with a constructed reality that allows the 'reel' to be more factual than the 'real'. Eventually the dehumanizing factor of this technology is used to re-humanize refugees and migrants in order to construct a multi-perceptual field of view of the common humanity shared between civilized people. "We wanted to use the technology against itself to create an immersive, humanist art form, allowing the viewer to meditate on the profoundly difficult and frequently tragic journeys of refugees"

The governments' use of communication technology (broadcast television /social media etc.) and bio-politics, along with mobile media and connectivity that is easily accessible to the public has caused an oversaturation of images of refugees and migrants. This consistency of projected images of refugees, migrants and asylum seekers and continuous bombardment of these images has decreased positive feelings to the plight of refugees in the point of view of government and society. Moreover, this proliferated image of refugees and migrants has become representationally constructed visual entities rather than images of real living human beings.

\section{FROM THE 'REEL' TO THE 'REAL'}

A preliminary examination of media sources and records has revealed a huge discrepancy in the way western media outlets have represented Palestinians since the 1948 Exodus to this day. In comparison with today's representation of Syrian refugees, we find much bias from media coverage towards the Palestinian migrants and refugees, as well those still living under illegal occupation of Palestine.

Imagery of Palestinians is limited compared to the abundant saturation of Syrian refugees and political strife content since the beginning of the Syrian Civil War in 2011. Western Media Coverage of the 
Palestinian situation tends to insistently omit information, decontextualize it and use unverified and selective reporting of the Palestinian migrant situation and the quagmire of forced occupation. Therefore with Palestinians, instead of saturating the imagery of refugees, the image is made void in opposition of the overloaded imagery of Syrian refugees in terms of content and level of global saturation.

We will review and analyse archival reel records from Lebanese and foreign TV stations and media outlet sources that utilized communication technology (i.e., electronic news gathering, satellite, social media etc...) and supplement this by conducting an in depth comparison in the way various media outlets presented the recent Syrian refugee crisis with the non-recent Palestinian migrants in Lebanon in order to gauge to what extent the use of communication technology affects public perception.

\section{REFERENCES}

Revel, J. (2014). Identity, nature, life: Three biopolitical deconstructions. The Government of Life: Foucault, Biopolitics, and Neoliberalism, 112-24.

Burton, A., \& John-Leader, F. (2009). Are we reaching refugees and internally displaced persons? Bulletin of the World health Organization, 87, 638-639per.

Merlingen, M. (2003). Governmentality: Towards a Foucauldian framework for the study of IGOs. Cooperation and Conflict, 38(4), 361-384.

Prodnik, J. A. (2014). A seeping commodification: the long revolution in the proliferation of communication commodities. tripleC: Communication, Capitalism \& Critique. Open Access Journal for a Global Sustainable Information Society, 12(1), 142-168.

Minca, C. (2015). Geographies of the camp. Political Geography, 49, 74-83.

Lechte, J. (2007). Civil identity and 'bare life': Arendt and Agamben's challenge to human rights.

Andrade, A. D., \& Doolin, B. (2016). Information and communication technology and the social inclusion of refugees. Mis Quarterly, 40(2), 405416.
Foster, H. (1995). The artist as ethnographer?. The traffic in culture: refiguring art and anthropology, 302-309.

Stepanova, E. (2011). The role of information communication technologies in the "Arab Spring". Ponars Eurasia, 15(1), 1-6.

Baranoff, J., Gonzales, R. I., Liu, J., Yang, H., \& Zheng, J. (2015, April). Lantern: Empowering refugees through community-generated guidance using near field communication. In Proceedings of the 33rd Annual ACM Conference Extended Abstracts on Human Factors in Computing Systems (pp. 7-12). ACM.

Bennett, B. (2018). Becoming refugees: Exodus and contemporary mediations of the refugee crisis. Transnational Cinemas, 9(1), 13-30.

Leung, L. (2010). Telecommunications across borders: Refugees' technology use during displacement. Telecommunications Journal of Australia.

Bjorgo, E. (2000). Refugee camp mapping using very high spatial resolution satellite sensor images. Geocarto International, 15(2), 79-88.

O'Neill, M. (2008, May). Transnational refugees: The transformative role of art? In Forum: Qualitative Sozialforschung. = Forum: qualitative social research. (Vol. 9, No. 2, p. 59). Freie Universität Berlin.

Sawhney, N. (2009, June). Voices beyond walls: the role of digital storytelling for empowering marginalized youth in refugee camps. In Proceedings of the 8th International Conference on Interaction Design and Children (pp. 302-305). ACM.

Lodhi, M. A., Echavarria, F. R., \& Keithley, C. (1998). Using remote sensing data to monitor land cover changes near Afghan refugee camps in northern Pakistan. Geocarto International, 13(1), 33-39.

Johnson, M., Evans, G., Mohamed, Z., \& Caress, A. L. (2006). The development and evaluation of alternative communication strategies to facilitate interactions with Somali refugees in primary care: a preliminary study. Journal of Innovation in Health Informatics, 14(3), 183-189. 
Gillespie, Marie \& Ampofo, Lawrence \& Cheesman, Margaret \& Faith, Becky \& Iliadou, Evgenia \& Issa, Ali \& Osseiran, Souad \& Skleparis, Dimitris. (2016). Mapping Refugee Media Journeys: Smartphones and Social Media Networks. 10.13140/RG.2.2.15633.22888.

Data2.unhcr.org. (2019). Situation Syria Regional Refugee Response. [online] Available at: https://data2.unhcr.org/en/situations/syria/locatio n/71 [Accessed 14 Oct. 2019]. 